\title{
3D Numerical Simulation of Reinforced Concrete Lining's Cracking Behavior in Tunnels
}

\author{
Wenzheng $\mathrm{He}^{1,2}$, Linsheng $\mathrm{Xu}^{1, ~ *}$ and Lili Wang ${ }^{3}$ \\ ${ }^{1}$ Chongqing Municipal Key Laboratory of Mountain Highway \& Waterway Transportation Geological Disaster Reduction, Chongqing \\ Jiaotong University, Chongqing 400074, China \\ ${ }^{2}$ School of Urban Construction Engineering, Chongqing Radio \& Television University, Chongqing 401520, China \\ ${ }^{3}$ School of Management, Cardiff Metropolitan University, Cardiff, CF52YB, Wales
}

Received 6 June 2019; Accepted 14 August 2019

\begin{abstract}
Longitudinal cracks in actual tunnel linings are 3D semi-embedded. The fracture properties of lining are influenced by numerous factors, such as steel bar, fracture geometry, and boundary conditions. A 3D numerical model for analyzing the cracking behavior of reinforced concrete lining was proposed in this study. This model was used to investigate the fracture characteristics of $3 \mathrm{D}$ semi-embedded cracks on reinforced concrete lining in mountain tunnels. The approximation formula for stress intensity factors (SIFs) of the crack tip in reinforced concrete tunnel lining was deduced. Moreover, the numerical models of 3D semi-embedded and 2D edge cracks were constructed on the basis of the finite element method. The outcomes of the $2 \mathrm{D}$ and $3 \mathrm{D}$ models were compared via case study. The effects of tensile reinforcement ratio, position of reinforcing bars, and the relative height and angle of the cracks on SIF were discussed. Results demonstrate that the SIF of 3D semi-embedded cracks is less than $50 \%$ of that of $2 \mathrm{D}$ edge cracks. The SIF of the crack tip decreases significantly after considering the effect of steel bars, and it is negatively related to the tensile reinforcement ratio and longitudinal propagation of lining crack prior to vertical propagation. This study serves as a reference for designing secondary linings in tunnels.
\end{abstract}

Keywords: Reinforced concrete lining, Cracks, Stress intensity factor, Propagation

\section{Introduction}

The continuous expansion of tunnel construction scale and the increase in tunnel service time has caused the gradual degradation of lining structure, wherein crack is a principal defect. About $80 \%$ of tunnels built in China more than 10 years ago have lining cracks in varying degrees, which may also occasionally exist in newly constructed tunnels [1]. Cracks not only affect the beauty and endurance of lining structures, destroy the structural integrity of the infrastructure, and shorten the service life of tunnels. They may also cause the overall collapse of the lining structure in serious cases, resulting in huge economic losses and adverse social effects. Hence, reinforced concrete structure is often applied in tunnel lining at regions with poor surrounding rock conditions or in portal sections. Steel bars can inhibit or delay further crack propagation and prevent brittle failure of the concrete structure due to rapid crack propagation, which is conducive to improving the bearing capacity of linings effectively [2].

However, studies show that reinforced concrete lining's cracking behavior is sensitive to multiple factors. Analyzing fracture parameters is increasingly difficult because cracks in actual tunnel lining structures are generally complicated 3D nonplanar. Therefore, a rapid and accurate assessment of

*E-mail address: phoniex8210@sina.com

ISSN: 1791-2377 @ 2019 School of Science, IHU. All rights reserved.

doi:10.25103/jestr.124.20 the safety and failure behaviors of actual lining structures is difficult to achieve.

The cracking behaviors of linings have been the subject of many studies [3-7]. However, the numerical calculation model of cracks on reinforced concrete structures deviates from the actual working state to a certain extent, and relevant theoretical studies are lacking. Hence, quantitatively investigating the performance of steel bars in the crack arresting of tunnel lining structures and accurately calculating the fracture parameters of lining structures with complicated 3D cracks are interesting and meaningful research endeavors.

An approximation formula for the SIF of crack tip at the vault was deduced in this study, and a numerical model of reinforced concrete lining crack was constructed on the basis of finite element method (FEM). The influences of steel bar parameters, fracture geometry, and boundary conditions on SIF were also discussed, and the $3 \mathrm{D}$ propagation path of cracks was analyzed to provide references to the reinforcement design of tunnel lining structures.

\section{State of the art}

A series of investigations on the fracture behaviors of concrete structures have been performed. However, only a few scholars have studied fracture mechanics of concrete structures based on tunnel engineering cases. The majority of the findings on the causes of tunnel lining cracks are 
general and qualitative. The numerical studies on cracks have performed qualitative analysis on the possible positions of cracks from the perspectives of stress and deformation, but works that used intuitive and quantitative methods are lacking. Moreover, the theoretical system on crack stability is not comprehensive enough. Bosco et al. [8] studied the failure behavior of reinforced beams with edge cracks in a matrix by using the SIF at the crack tip, and equal and opposite forces were applied on the crack surface to simulate the restraint of steel bars. However, this method was limited to $2 \mathrm{D}$ cracks. On the basis of the fracture mechanical theory and virtual crack model, Yang et al. [9] analyzed the influences of reinforcement modes on the inhibition of crack propagation on the panel surface of a rock-fill dam and found that single-layer reinforcement was superior to double-layer reinforcement under the same tensile reinforcement ratio. However, this method was inapplicable to the tunnel lining structure. Azad [10] determined the fracture energy of reinforced concrete beams through experimentation. Ruiz [11] studied the fracture of lightly reinforced concrete beams via experimentation and found that the size effect of ultimate bearing capacity was proportional to the tensile reinforcement ratio. Chambel [12] proposed I, II, III, or mixed-mode fatigue crack propagation modes under plane strain and plane stress conditions on the basis of the FEM but ignored the fracture parameters of 3D cracks. Rabold et al. [13-14] presented a finite element software for automated simulation of fatigue crack growth in arbitrarily loaded 3D components. They calculated SIF range by combining submodel and interaction integral technologies. However, this software neglected the restraining effect of reinforcing bars on cracks and was inapplicable to reinforced concrete structures. $\mathrm{Li}$ et al. [15] developed an automatic simulation method of 3D nonplanar crack propagation on the basis of FEM. Bremberg et al. [16] proposed a numerical calculation method of composite SIF. The complex fracture problem of tunnel lining structures is often solved by using numerical approaches due to complicated structural forms and boundary conditions of tunnels. $\mathrm{Xu}$ [17] analyzed the fracture behavior of longitudinal cracks on lining at tunnel vaults on the basis of the theory of fracture mechanics and offered a SIF formula under simple loads. Meanwhile, the influencing law of crack depth on SIF was determined through a numerical analysis of the tunnel lining structure, but the results were inapplicable to reinforced concrete lining structures. Xu et al. [18] explored the fracture mechanics of plain concrete and single- and double-steel bar sections in hydraulic tunnels with pressure. They also deduced the SIF under different internal hydraulic pressures and determined the double-K fracture parameters of the abovementioned lining structures, but neglected 3D effect. Fan et al. [19] numerically simulated tunnel dmage by using the extended FEM (XFEM) and implemented a tunnel model experiment. Their results showed that the XFEM of the tunnel could simulate the propagation path of initial cracks well, and the tunnel model had evident shearing failure. Compressive strength reached the maximum when the flatness ratio was 1.7 . Huang et al. [20] performed a field investigation and statistical analysis on crack defects of tunnel lining structures in 48 highways in Zhejiang Province, China. The distribution characteristics of cracks on highway tunnel lining structures and the main influencing factors of lining cracking behavior were revealed. Moreover, the crack distribution pattern, crack propagation process, crack appearance, and generation mechanism of lining structures under external loads were discussed through
XFEM. On the basis of the theory of mechanics of concrete fractures, Zhang et al. [21-22] investigated the influencing laws of crack depth, crack width, and number of cracks on the safety of tunnel lining structures by using the planar FEM. Wang [23] proposed a fracture criterion on plain concrete lining structures on the basis of the theory of mechanics of concrete fractures and calculated the SIF at the crack tip with the fracture module of ANSYS. However, this method is limited to plain concrete linings.

These studies have mainly focused on the fracture characteristics of plain concrete structures. However, quantitative assessments of the crack arresting effect of steel bar on lining structures are limited. Only a few studies have discussed the fracture problems of reinforced concrete lining structures with 3D cracks. SIF is an important mechanical parameter for assessing structural safety and failure behaviors of tunnel linings. In the present study, an approximation formula of SIF for cracks at the vault of reinforced concrete lining structures was deduced by using the theory of mechanics of fractures. The SIF calculation models for 2D edge and 3D semi-embedded cracks in tunnel lining structures were constructed using ANSYS software. Considering the influences of fracture geometry and steel bar, a numerical analysis of the $3 \mathrm{D}$ cracking problem of reinforced concrete lining structures was implemented. The influences of the main parameters on SIF and 3D propagation path of cracks were discussed. This study is expected to serve as a reference for the reinforcement design of tunnel lining structures.

The remainder of this study is organized as follows. Section 3 presents the constructed numerical model of reinforced concrete lining cracks and deduced approximation formula of SIF for cracks at the vault. Section 4 discusses the effects of the tensile reinforcement ratio, reinforcement position, crack angle, and relative depth on SIF. Moreover, the 3D propagation path of lining cracks is explored by using the XFEM.Section 5 summarizes the conclusions.

\section{Methodology}

Longitudinal cracks, which are mostly found at the vault, are a threatening defect in tunnel engineering. These cracks are extremely short in comparison with the length of tunnels. According to statistics [24], more than $70 \%$ of longitudinal cracks are less than $10 \mathrm{~m}$ long, and crack depths reach a maximum of 0.5 times that of the lining thickness. Hence, longitudinal cracks in actual tunnel linings are 3D semiembedded cracks (Fig. 1) that will cause serious errors by using a simplified calculation, such as that of $2 \mathrm{D}$ edge cracks. The geometric description of 3D cracks is shown in Fig. 2.

In this study, the fracture behavior is analyzed on the basis of a typical profile of the Bapanshan Tunnel in Tianshui City, Gansu Province, China. The cracking characteristics of 3D cracks on reinforced concrete lining structures are also investigated. The main research contents are presented as follows:

(1) An approximation formula of SIF at the crack tip on the lining vault is derived.

(2) A numerical model of 2D edge crack in reinforced concrete lining is constructed, and the SIF of crack tip is calculated. 
(3) A numerical model of 3D semi-embedded crack in reinforced concrete lining is constructed, and the SIF of crack front is calculated.

(4) The spatial propagation path of 3D semi-embedded cracks is calculated.

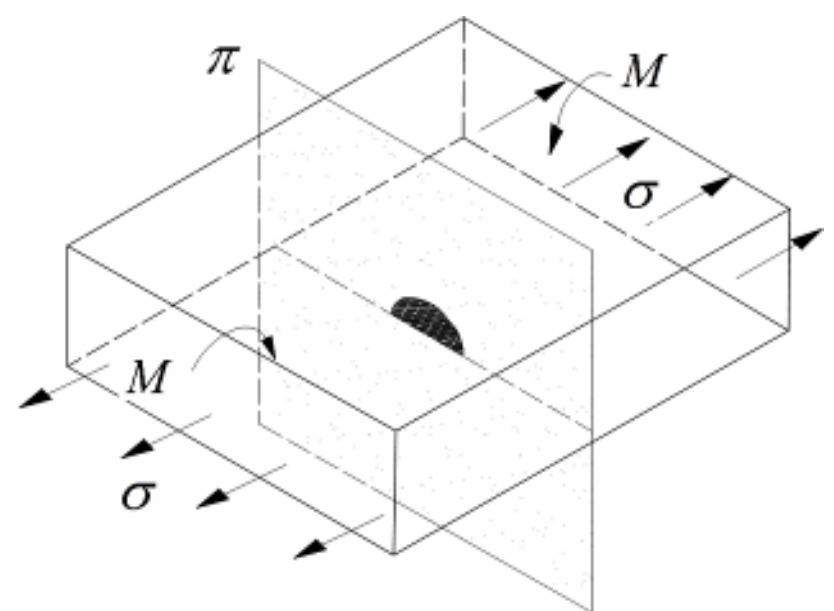

Fig. 1. 3D semi-embedded crack

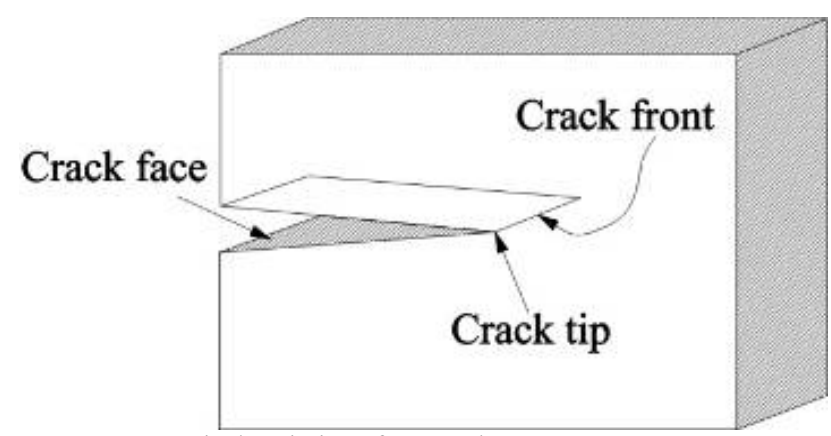

Fig. 2. Geometric description of 3D cracks

\subsection{Deduction of an approximation formula of SIF for tunnel lining cracks}

For mountain highway tunnels, a section is generally a multicenter circle, and an arch can be approximately viewed as a section of an arc. The SIF of the crack tip at the vault can be approximately expressed by using the SIF of threepoint bending specimens of an arched beam as follows [25]:

$K_{I C}=F K_{0}$

where $K_{I C}$ is the SIF produced by using external loads at the vault crack tip. $K_{0}=\frac{P L}{4 H\left(\sqrt{h_{d}}\right)^{3}}$, where $P$ is the concentrated force on the arched beam; $L$ is the span; $H$ is the height of the arched beam; $M$ is the bending moment of vault; $h_{d}$ is the thickness; $F$ is the shape influence coefficient.

The effects of the steel bar are neglected in Eq. (1). With consideration for the crack propagation inhibition of steel bars, the superposition principle indicates that.

$K_{I T}=K_{I C}-K_{I S}$

where $K_{I T}$ is the SIF at the reinforced lining vault, and $K_{I S}$ is the SIF produced by the steel bar constraining force at the crack tip of the vault. Eq. (2) shows that the closing force of steel bar generates a reversed SIF that hinders crack propagation and decreases the SIF of cracks from $K_{I C}$ to $K_{I C}-K_{I S}$. The reduction amplitude is only equal to the SIF ( $K_{I S}$ ) produced by the closing force $F_{S}$. The calculation process is presented in Fig. 3. $K_{I S}$ can be calculated according to the following formula used in [2]:

$$
K_{I S}=\frac{2 F_{S}}{B \sqrt{\pi a}} F(\alpha, \beta)
$$

The $F(\alpha, \beta)$ can be expressed as follows:

$$
\begin{aligned}
& F(\alpha, \beta)=\frac{3.52(1-\alpha)}{(1-\beta)^{\frac{3}{2}}}-\frac{4.35-5.28 \alpha}{(1-\beta)^{\frac{1}{2}}}+ \\
& {\left[\left(\frac{1.3-0.3 \alpha^{\frac{1}{2}}}{\left(1-\alpha^{2}\right)^{\frac{1}{2}}}+0.83-1.76 \alpha\right)(1-\beta(1-\alpha))\right]}
\end{aligned}
$$

where $\alpha=\frac{c}{a}, \beta=\frac{a}{h_{d}}, c$ is the distance between the steel bar center and bottom of the component; $a$ is the initial length of crack; $F_{S}$ is the constraining force of the steel bar.

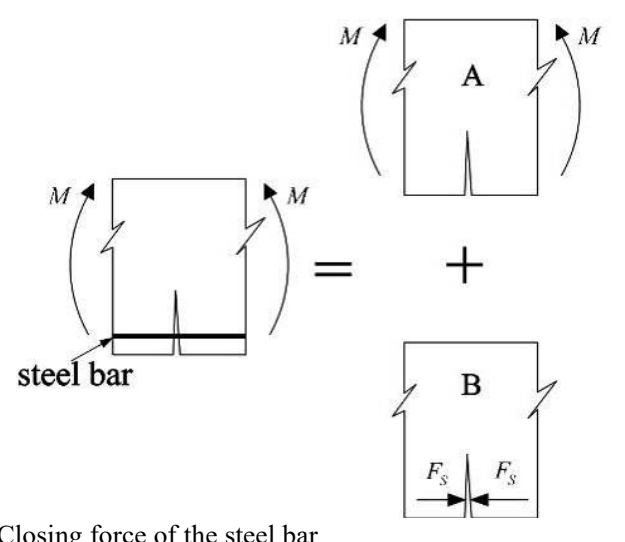

Fig. 3. Closing force of the steel bar

\subsection{Numerical calculation model}

The section of Bapanshan tunnel (Fig. 4) is three-centered circle with an arch radius of $5.5 \mathrm{~m}$. The major calculation parameters of this tunnel are listed in Tables 1 and 2. The plane geometry of lining crack is shown in Fig. 5, and the geometric description of 3D semi-embedded cracks is presented in Fig. 6. SIF was solved by using the interaction integral method with the fracture module of ANSYS. Only the SIF of I-type crack tip $\left(K_{\mathrm{I}}\right)$ was calculated in this study because I-type cracks are the most common and threatening ones.

Table 1. Geometric parameters of tunnel

\begin{tabular}{c|c|c}
\hline$H(m)$ & $B(m)$ & $h_{d}(m)$ \\
9.14 & 11.78 & 0.45 \\
\hline
\end{tabular}

Table 2. Material parameters of tunnel

\begin{tabular}{c|c|c|c|c}
\hline Materials & $\begin{array}{c}\text { Elastic } \\
\text { Modulus } \\
(G p a)\end{array}$ & $\begin{array}{c}\text { Poisson's } \\
\text { ratio }\end{array}$ & $\begin{array}{c}\text { Coefficient } \\
\text { of elastic } \\
\text { reaction } \\
(\mathrm{MPa} / \mathrm{m})\end{array}$ & $\begin{array}{c}\text { Unit weight } \\
\left(\mathrm{kN} \cdot \mathrm{m}^{-3}\right)\end{array}$ \\
\hline Concrete & 29.5 & 0.20 & $/$ & 25 \\
\hline
\end{tabular}




\begin{tabular}{c|c|c|c|c}
\hline $\begin{array}{c}\text { Surrounding } \\
\text { rocks }\end{array}$ & 5.0 & 0.35 & 200 & 22 \\
\hline steel bar & 206 & 0.30 & $/$ & 78 \\
\hline
\end{tabular}

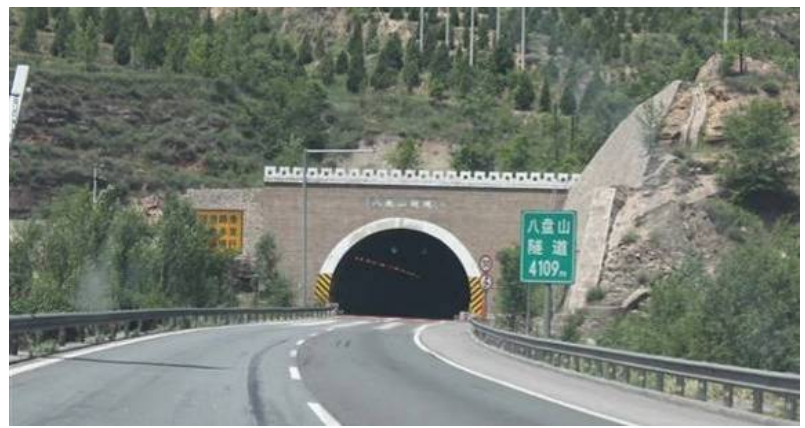

Fig. 4. Photo of the Bapanshan tunnel

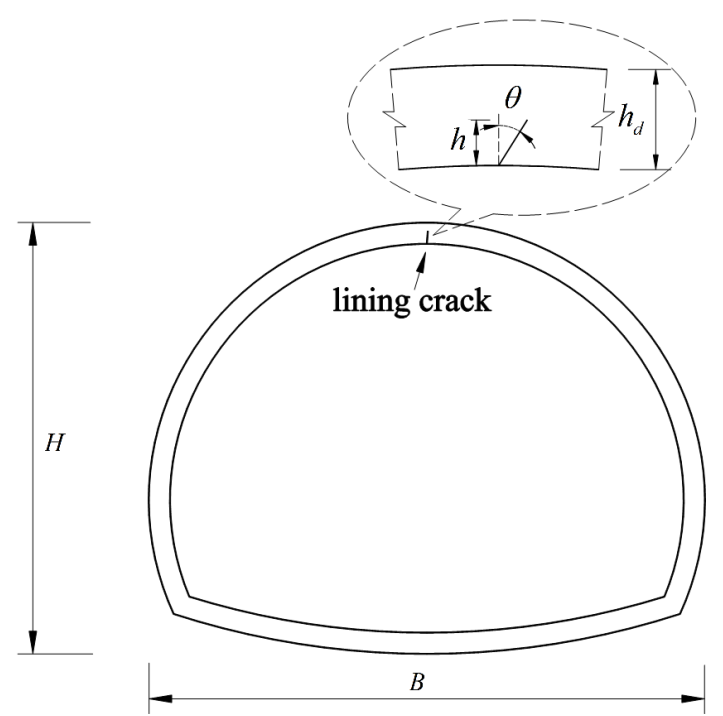

Fig. 5. Plane geometry of lining crack

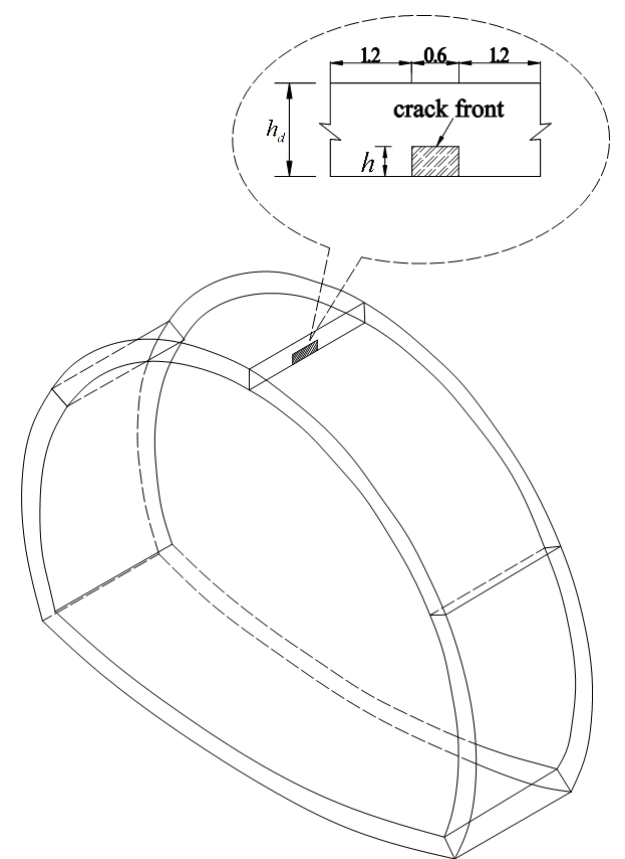

Fig. 6. 3D semi-embedded cracks in the tunnel lining

3.2.1 Numerical model of SIF for 2D edge cracks in reinforced concrete lining structures

Lining was simulated by using plane 183 elements, whereas the surrounding rocks were simulated by using link 10 elements set to the compression-only state. The steel bar was simulated by applying link8 elements. Steel bar and lining concrete were bonded through the node-coupled equation. Singular elements were set at the crack tip by using the fracture module of ANASYS, thus simulating the singularity of the crack tip. SIF was solved via the extrapolation method of $1 / 4$ node displacement. The local model of the crack tip at the vault is shown in Fig. 7.

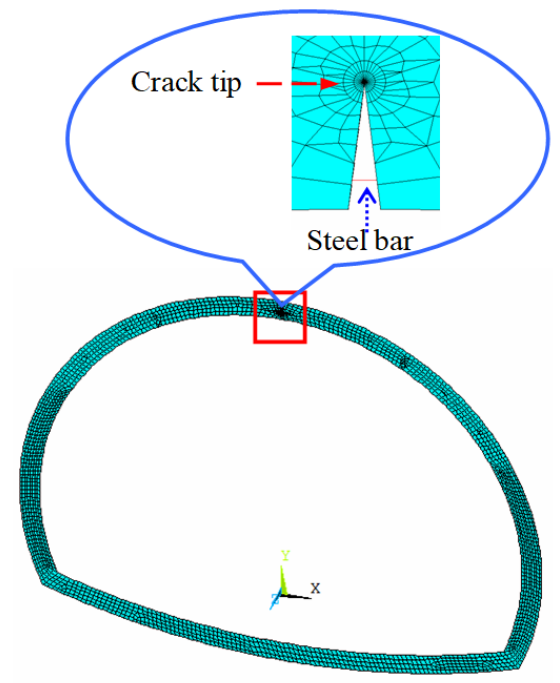

Fig. 7. 2D edge crack meshing

3.2.2 Numerical model of SIF for the 3D semi-embedded crack in the reinforced concrete lining structure

Parameterized modeling method was applied in this study. The lining was simulated by using solid186 elements, whereas the surrounding rock was simulated by applying link10 elements set to compression-only state. Steel bar was simulated by using link8 elements. The 2D edge crack model was stretched into solid grids. Nodes at the same positions of other regions out of the crack can be combined to form 3D semi-embedded cracks. The finite element meshing of the 3D semi-embedded crack is shown in Fig. 8. Similar to the 2D fracture analysis, SIF of the 3D crack can be calculated by using the extrapolation method of $1 / 4$ node displacement.

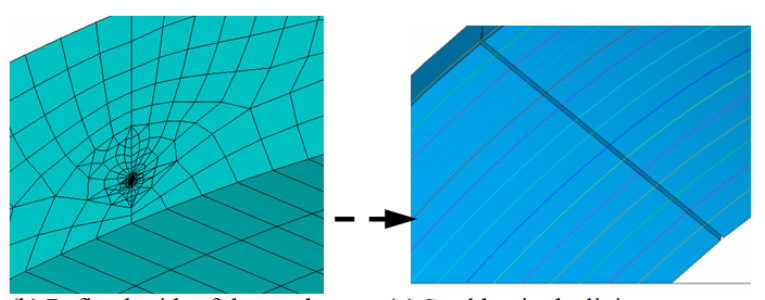

$\begin{array}{ll}\text { (b) Refined grids of the cracks } & \text { (c) Steel bar in the lining structure }\end{array}$

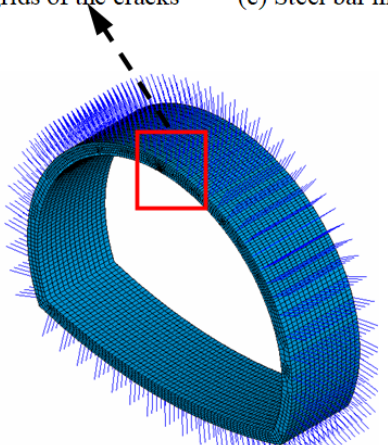

(a) Global model

Fig. 8. 3D semi-embedded crack meshing 


\subsubsection{Numerical model of 3D semi-embedded crack} propagation

The 3D semi-embedded crack propagation path was calculated via XFEM. The modeling method was consistent with the calculation model of SIF, and the cracks were prefabricated at the vault elements of lining by using the level set method.

\section{Result Analysis and Discussion}

\subsection{Calculation of SIF}

The relative height and angle of cracks were set to 0.2 and $0^{\circ}$, respectively. The thickness of the protection layer was $0.035 \mathrm{~m}$. A concentrated load $\mathrm{p}=2 \times 10^{5} \mathrm{~N}$ was applied at the vault. Theoretical analysis and numerical simulation analysis results under different relative heights of the cracks are listed in Table 3.

Table 3. Comparison of the calculation results

\begin{tabular}{c|c|c|c}
\hline$h_{d} / h$ & $\begin{array}{c}\text { Calculated results of the } \\
\text { approximation } \\
\text { formula }(\mathrm{Mpa} \cdot \sqrt{\mathrm{m}})\end{array}$ & $\begin{array}{c}\text { Numerical simulation } \\
\text { results }(\mathrm{Mpa} \cdot \sqrt{\mathrm{m}})\end{array}$ & Error \\
\hline 0.20 & 2.42 & 2.34 & $3.42 \%$ \\
0.25 & 2.83 & 2.55 & $10.98 \%$ \\
0.30 & 3.26 & 2.95 & $10.51 \%$ \\
0.35 & 3.63 & 3.16 & $14.87 \%$ \\
\hline
\end{tabular}

Table 3 shows that the calculated results of the approximation formula are similar to the numerical simulation results when the relative height is 0.2. However, the error increased gradually with the increase in relative height of cracks. The relative error reached $14.87 \%$ when the relative height was 0.35 . The basic hypothesis of the approximation formula deviated from practical experience to a certain extent, and the influences of parameters, such as crack angle and reinforcement position, are neglected. Hence, only a general estimation could be offered. The numerical analysis results of the fracture parameters obtained high accuracy due to the complicated structural forms and boundary conditions of the tunnel-reinforced concrete lining.

\subsubsection{Comparison of SIF between 2D edge and 3D semi-} embedded cracks

The relative height and angle of cracks were set to 0.2 and $0^{\circ}$, respectively. The effects of reinforcement and fracture geometry were neglected. Comparisons of the analysis results of $2 \mathrm{D}$ edge, $3 \mathrm{D}$ edge, and $3 \mathrm{D}$ semi-embedded cracks are presented in Table 4 and Fig. 9. The cracks are shown in Figs. 10 and 11.

Table 4. $K_{\mathrm{I}}$ of the crack front

\begin{tabular}{c|c|c|c|c|c|c|c}
\hline Fracture & \multicolumn{6}{|c}{ Coordinates of nodes on the crack front (m) } \\
\cline { 2 - 8 } form & $\mathbf{1 . 2}$ & $\mathbf{1 . 3}$ & $\mathbf{1 . 4}$ & $\mathbf{1 . 5}$ & $\mathbf{1 . 6}$ & $\mathbf{1 . 7}$ & $\mathbf{1 . 8}$ \\
\hline $\begin{array}{c}\text { 2D edge } \\
\text { crack }\end{array}$ & 4.25 & 4.25 & 4.25 & 4.25 & 4.25 & 4.25 & 4.25 \\
$\begin{array}{c}\text { 3D edge } \\
\text { crack }\end{array}$ & 4.10 & 4.10 & 4.10 & 4.10 & 4.10 & 4.10 & 4.10 \\
$\begin{array}{c}\text { 3D semi- } \\
\text { embedded } \\
\text { crack }\end{array}$ & 1.30 & 1.83 & 2.01 & 2.09 & 2.01 & 1.83 & 1.30 \\
\hline
\end{tabular}

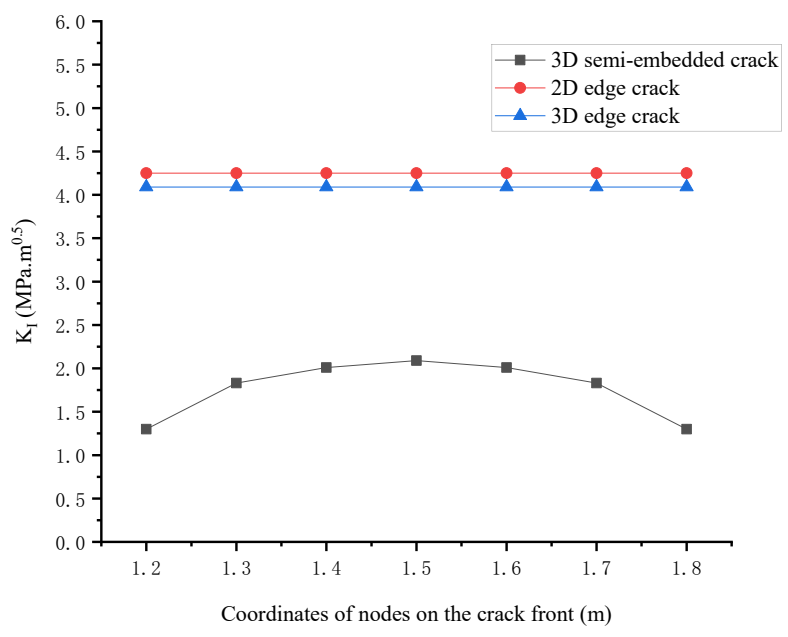

Fig. 9. Comparison of the analysis results

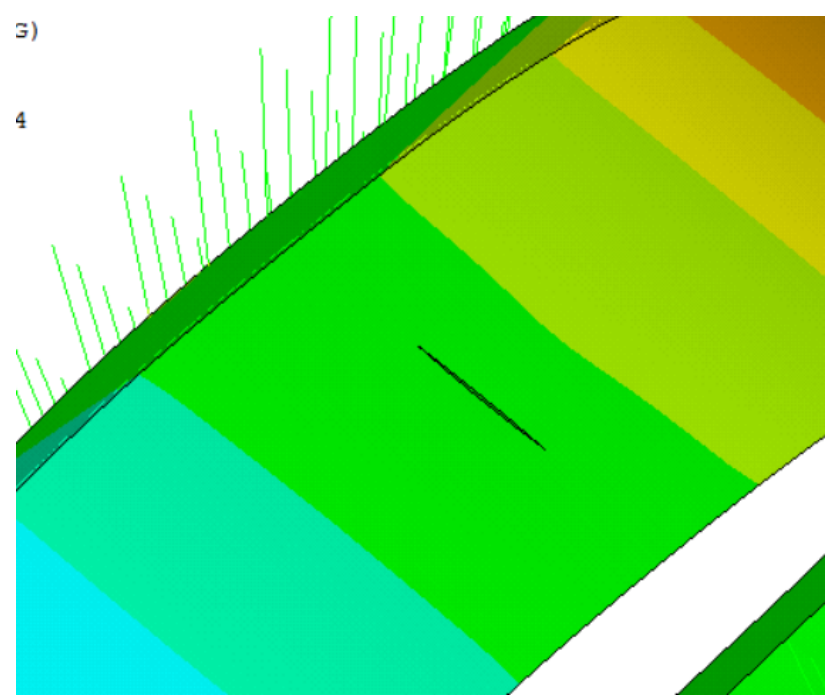

Fig. 10. Deformation of 3D semi-embedded cracks

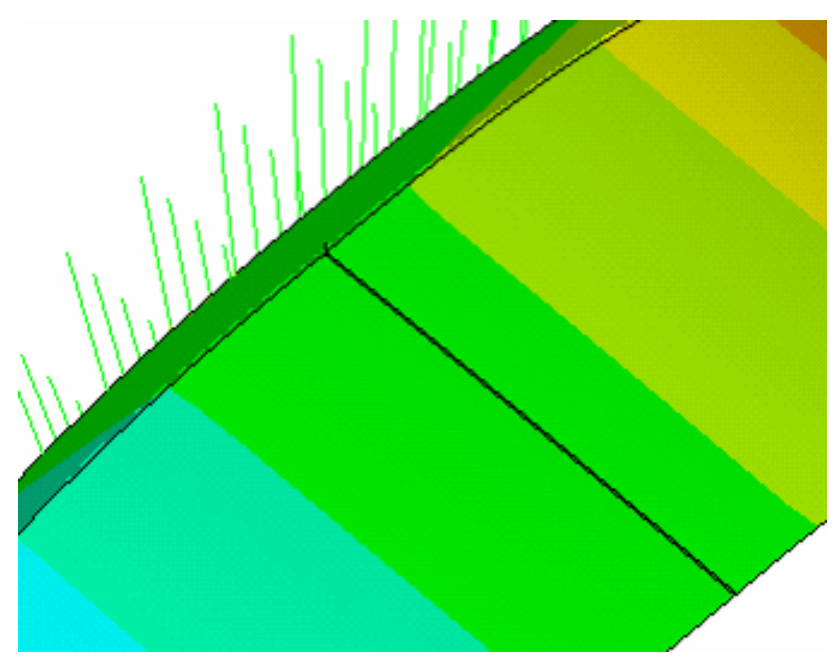

Fig. 11. Deformation of $3 D$ edge crack

According to the calculated results, the SIF values of 2D edge and $3 \mathrm{D}$ edge cracks were relatively consistent with a relative error of less than $4 \%$, thereby confirming the accuracy of the model-calculated results. However, the SIF of the 2D edge crack obtained a large error with SIF of the 3D semi-embedded crack. SIF of the 3D semi-embedded crack was less than $50 \%$ that of the $2 \mathrm{D}$ edge crack under the same conditions because the constraint of concrete at the two 
ends of the cracks to the crack was ignored, and the crack was easily propagated. Accordingly, the $K_{\mathrm{I}}$ distribution was uneven on the crack front. $K_{I}$ in the middle was higher than those at the two sides and demonstrated a difference of nearly $40 \%$.

\subsubsection{Effects of fracture geometry on $K_{\mathrm{I}}$}

$K_{\mathrm{I}}$ under different crack angles and relative heights without consideration for reinforcement was calculated. A 3D surface diagram was drawn on the basis of the calculated results (Figs. 12-13).

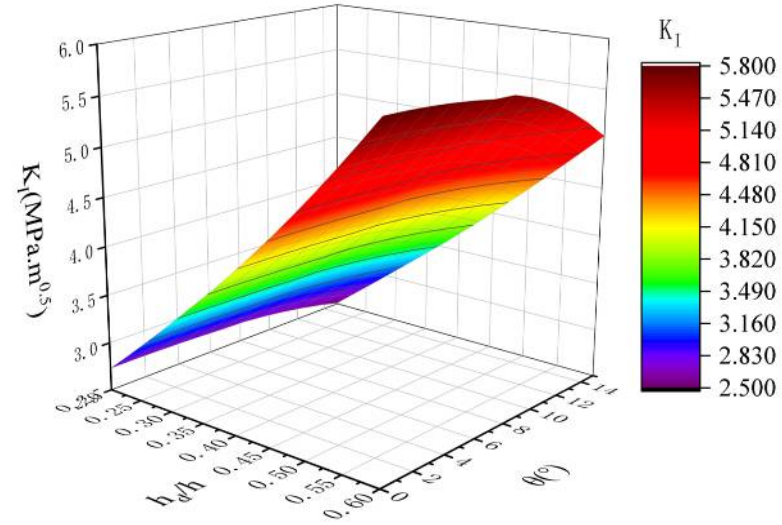

Fig. 12. Influences of relative height and angle of cracks on $K_{\mathrm{I}}(2 \mathrm{D}$ edge crack)

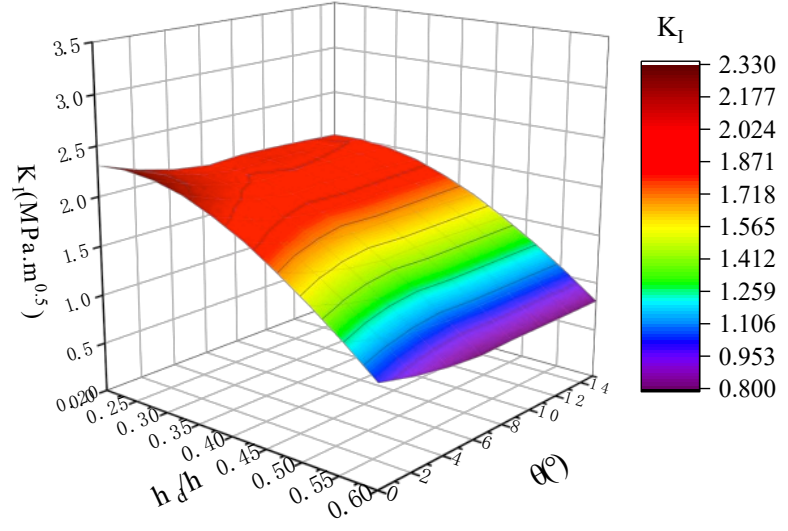

Fig. 13. Influences of relative height and angle of cracks on $K_{\mathrm{I}}$ (3D semi-embedded crack)

The influence coefficient of fracture geometry was defined as $f_{g}$, which is the ratio of current SIF relative to $K_{\mathrm{I}}$ when $h / h_{d}=0.4$ and $\theta=0^{\circ} \cdot f_{g}$ of the 2D edge crack is presented in Table 5, and $f_{g}$ of the $3 \mathrm{D}$ semi-embedded crack front $(\mathrm{z}=1.5)$ is listed in Table 6 .

Table 5. $f_{g}$ of the $2 \mathrm{D}$ edge crack

\begin{tabular}{c|c|c|c|c|c}
\hline \multirow{2}{*}{$\theta$} & \multicolumn{5}{|c}{$h / h_{d}$} \\
\cline { 2 - 6 } & 0.2 & 0.3 & 0.4 & 0.5 & 0.6 \\
\hline $0^{\circ}$ & 0.67 & 0.83 & 1.00 & 1.20 & 1.41 \\
$5^{\circ}$ & 0.66 & 0.82 & 0.99 & 1.19 & 1.40 \\
$10^{\circ}$ & 0.65 & 0.81 & 0.97 & 1.16 & 1.36 \\
$15^{\circ}$ & 0.61 & 0.75 & 0.90 & 1.06 & 1.23 \\
\hline
\end{tabular}

Table 6. $f_{g}$ of the $3 \mathrm{D}$ semi-embedded crack

\begin{tabular}{c|c|c|c|c|c}
\hline \multirow{2}{*}{$\theta$} & \multicolumn{5}{|c}{$h / h_{d}$} \\
\cline { 2 - 6 } & $\mathbf{0 . 2}$ & $\mathbf{0 . 3}$ & $\mathbf{0 . 4}$ & $\mathbf{0 . 5}$ & $\mathbf{0 . 6}$ \\
\hline $0^{\circ}$ & 1.15 & 1.13 & 1.00 & 0.78 & 0.49 \\
$5^{\circ}$ & 1.02 & 1.00 & 0.88 & 0.67 & 0.41 \\
$10^{\circ}$ & 1.02 & 1.00 & 0.87 & 0.67 & 0.40 \\
$15^{\circ}$ & 1.00 & 0.98 & 0.86 & 0.66 & 0.40 \\
\hline
\end{tabular}

The calculated results indicate that the relative height and angle of cracks can significantly influence $K_{\mathrm{I}}$. For 2D edge and $3 \mathrm{D}$ semi-embedded cracks, $K_{\mathrm{I}}$ is negatively correlated with the crack angle. An opposite correlation is found between the relative height of cracks and $K_{\mathrm{I}}$. The $K_{\mathrm{I}}$ of the $2 \mathrm{D}$ edge crack increases with relative height of cracks, whereas the $K_{\mathrm{I}}$ of 3D semi-embedded crack declines gradually. This result is mainly because the constraint of concrete at the two sides of the 3D semi-embedded crack to the crack propagation is considered.

\subsubsection{Influences of steel bars on $K_{\mathrm{I}}$}

$K_{\mathrm{I}}$ under different tensile reinforcement $\operatorname{ratios}(\rho)$ and positions of reinforcing bars when relative height and angle of cracks are fixed $\left(h / h_{d}=0.4\right.$ and $\left.\theta=0^{\circ}\right)$ were calculated. The influence factor of steel bars $\left(f_{S}\right)$ as the ratio of $K_{\mathrm{I}}$ with and without reinforcement was defined. The calculated results are shown in Figs. 14-16 and Tables 7 and 8.

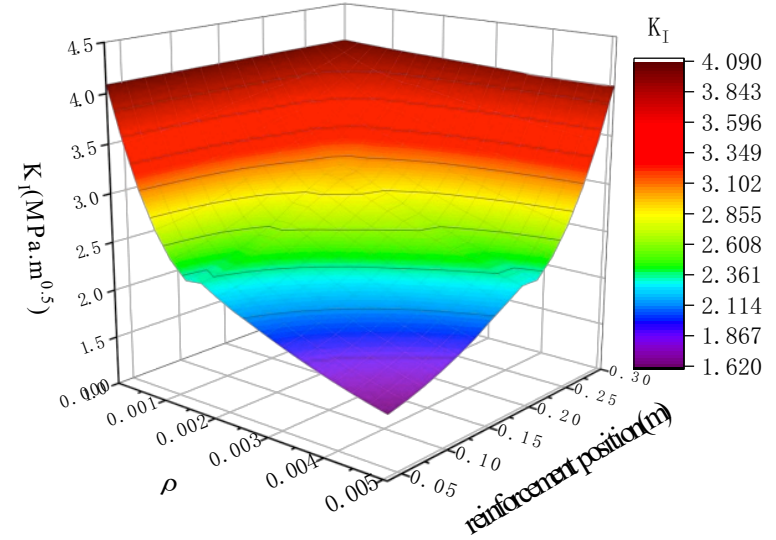

Fig. 14. Influences of steel bar on $K_{\mathrm{I}}$ (2D edge crack)

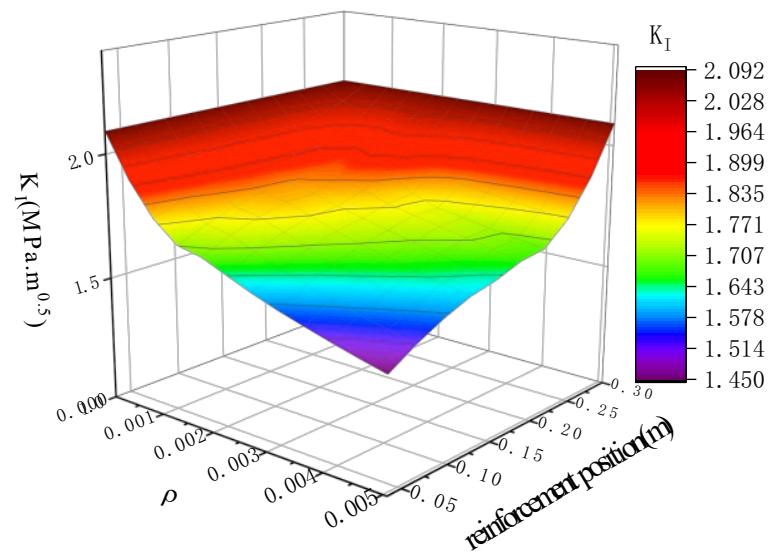

Fig. 15. Influences of steel bar on $K_{\mathrm{I}}$ (3D semi-embedded crack) 


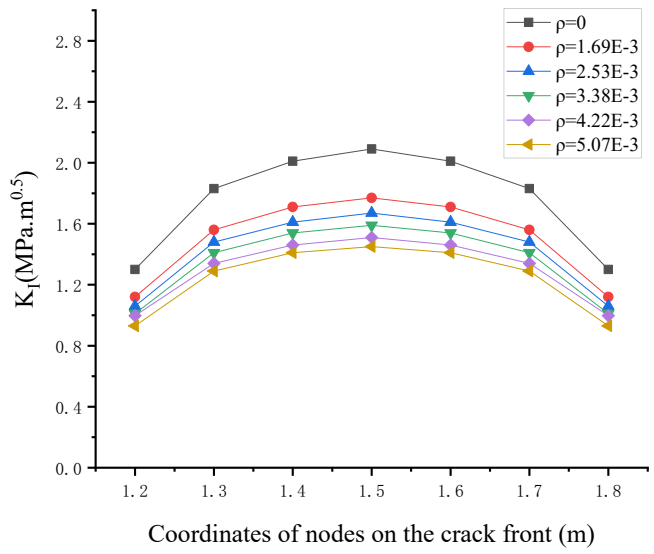

Fig. 16. Relation curve between $K_{\mathrm{I}}$ and $\rho$

Table 7. $f_{S}$ of the $2 \mathrm{D}$ edge crack

\begin{tabular}{c|c|c|c|c|c|c}
\hline Reinforcement & \multicolumn{7}{|c}{$\boldsymbol{\rho}(\mathbf{E}-\mathbf{0 3})$} \\
\cline { 2 - 7 } position (m) & $\mathbf{0 . 0 0}$ & $\mathbf{1 . 6 9}$ & $\mathbf{2 . 5 3}$ & $\mathbf{3 . 3 8}$ & $\mathbf{4 . 2 2}$ & $\mathbf{5 . 0 7}$ \\
\hline 0.035 & 1.00 & 0.64 & 0.55 & 0.49 & 0.44 & 0.40 \\
0.07 & 1.00 & 0.68 & 0.60 & 0.54 & 0.49 & 0.45 \\
0.10 & 1.00 & 0.76 & 0.68 & 0.62 & 0.57 & 0.54 \\
0.13 & 1.00 & 0.83 & 0.77 & 0.72 & 0.67 & 0.63 \\
0.30 & 1.00 & 1.00 & 1.00 & 1.00 & 1.00 & 1.00 \\
\hline
\end{tabular}

Table 8. $f_{S}$ of the $3 \mathrm{D}$ semi-embedded crack

\begin{tabular}{c|c|c|c|c|c|c}
\hline Reinforcement & \multicolumn{7}{|c}{$\boldsymbol{\rho}(\mathbf{E}-\mathbf{0 3})$} \\
\cline { 2 - 7 } position (m) & $\mathbf{0 . 0 0}$ & $\mathbf{1 . 6 9}$ & $\mathbf{2 . 5 3}$ & $\mathbf{3 . 3 8}$ & $\mathbf{4 . 2 2}$ & $\mathbf{5 . 0 7}$ \\
\hline 0.035 & 1.00 & 0.64 & 0.55 & 0.49 & 0.44 & 0.40 \\
0.07 & 1.00 & 0.68 & 0.60 & 0.54 & 0.49 & 0.45 \\
0.10 & 1.00 & 0.76 & 0.68 & 0.62 & 0.57 & 0.54 \\
0.13 & 1.00 & 0.83 & 0.77 & 0.72 & 0.67 & 0.63 \\
0.30 & 1.00 & 1.00 & 1.00 & 1.00 & 1.00 & 1.00 \\
\hline
\end{tabular}

According to calculated results, the influence coefficient of steel bar decreased with the increase of the tensile reinforcement ratio, thereby indicating the significant inhibition of steel bars to crack propagation. In the calculation of 3D semi-embedded cracks, such inhibition effect was weaker than that of the $2 \mathrm{D}$ edge crack. The reinforcement position could influence $K_{\mathrm{I}}$ significantly. $K_{\mathrm{I}}$ decreased with the increase in the thickness of the protection layer. However, $K_{\mathrm{I}}$ remained basically the same when the steel bar was located in the compressed regions.

\subsection{Propagation path of the 3D semi-embedded crack}

The propagation path of the 3D semi-embedded crack was calculated via XFEM. Vertical displacement was applied to the middle of vault. The calculated results are shown in Figs. 17-20.

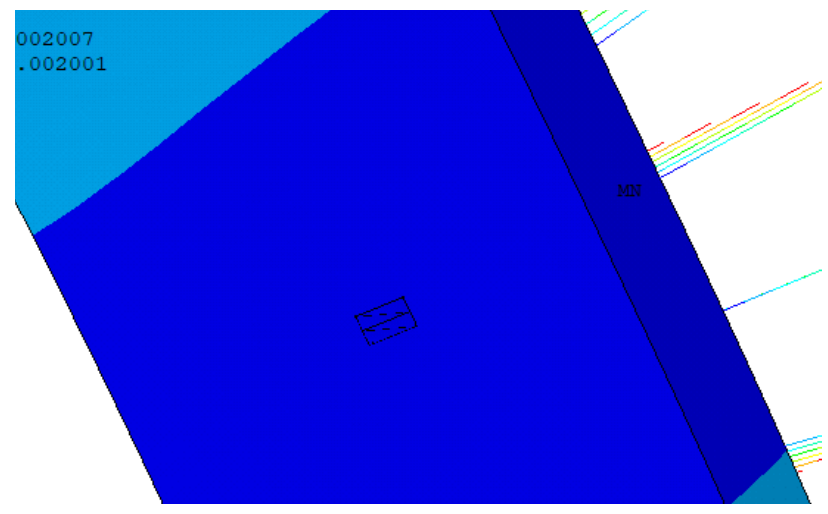

Fig. 17. Initial crack

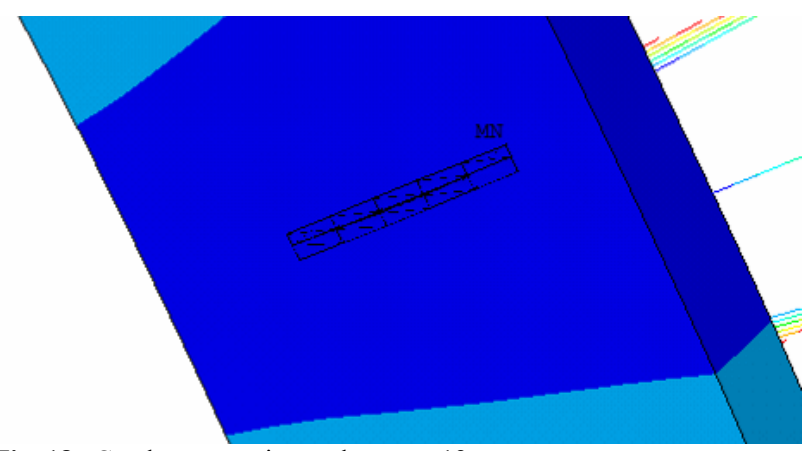

Fig. 18. Crack propagation path at step 12

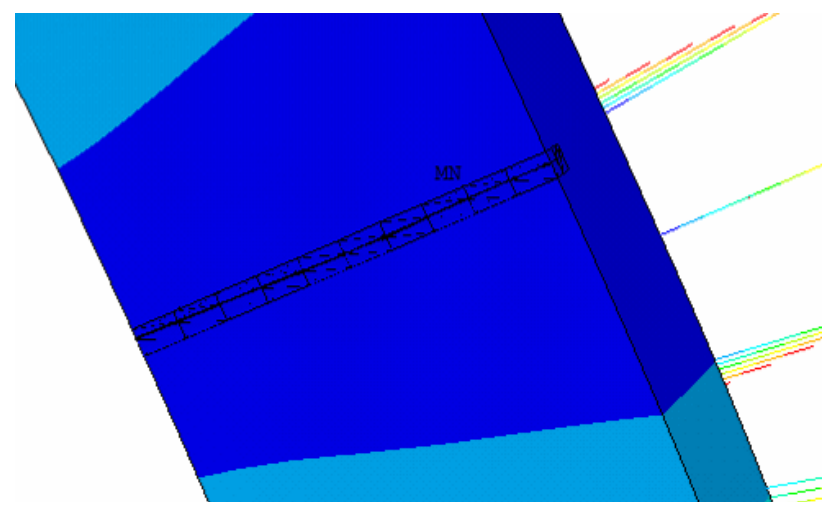

Fig. 19. Crack propagation path at step 17

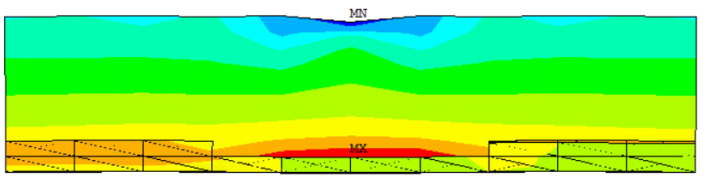

Fig. 20. Vertical crack propagation

The calculated results of the crack propagation path indicated that longitudinal propagation (along the length direction) first occurred in the concrete crack under concentrated loads at the vault, followed by simultaneous longitudinal and vertical (depth direction) propagations.

\section{Conclusions}

To explore the cracking characteristics in reinforced concrete lining structures in mountain tunnels and determine the stability of 3D semi-embedded cracks, theoretical and numerical calculation models of SIF of the reinforced concrete lining structure was proposed in this study. A case study was performed to analyze the SIF and crack propagation path of the $3 \mathrm{D}$ crack on a reinforced concrete structure obtained by using the proposed models. The following conclusions could be drawn from this study:

(1) The installation of ordinary steel bar in the lining structure could significantly reduce the SIF at the crack tip. SIF was negatively correlated with the tensile reinforcement ratio.

(2) The SIF of 3D semi-embedded cracks was less than $50 \%$ that of $2 \mathrm{D}$ edge cracks under the same mechanical conditions. The relative height of cracks oppositely affected the SIF of $2 \mathrm{D}$ and $3 \mathrm{D}$ cracks.

(3) Crack propagation along the length direction occurred earlier than that along the depth. 
A new understanding on the $3 \mathrm{D}$ analysis of fracture parameters of reinforced concrete lining structures was realized in this study by combining the theoretical investigations and numerical analysis. The constructed model was closer to practical field situations and could serve as a reference to the reinforcement design of secondary lining in tunnels. However, the proposed model must be verified using experimental data, which are conducive to achieving accurate understanding on crack initiation and the propagation laws of lining structures under complicated stress conditions.

\section{Acknowledgements}

This work was supported by Transportation Science project of Chongqing city (Grant Nos. 2015-03), Science project of Fuling District (Grant Nos. FLKJ2016BBB1082), and the Open Fund Project of Chongqing Jiaotong University Municipal Key Laboratory of Mountain Highway \& Waterway Transportation Geological Disaster Reduction (Grant Nos. kfxm2018-08).

This is an Open Access article distributed under the terms of the Creative Commons Attribution License

\section{References}

1. Hong, K., "Development and Prospects of Tunnels and Underground Works in China in Recent Two Years". Tunnel Construction, 37(2), 2017, pp. 14-25.

2. Shen, P., "Influence of Reinforcement Ratio on Concrete Fracture Parameters". Journal of Disaster Prevention and Mitigation Engineering, 33(2), 2013, pp. 235-240.

3. Nguyen, H. N., Kam, T. Y., Cheng, P. Y., "An automatic approach for accurate edge detection of concrete crack utilizing 2D geometric features of crack". Journal of Signal Processing Systems, 77(3), 2014, pp. 221-240.

4. Shan, B., Zheng, S., Ou, J., "A stereovision-based crack width detection approach for concrete surface assessment". KSCE Journal of Civil Engineering, 20(2), 2016, pp. 803-812.

5. Zhang, S., Chen, H., Wang, Y., "Diagnostic model of crack for tunnel lining based on gray and catastrophe theories". Journal of Traffic and Transportation Engineering, 3, 2015, pp. 34-40.

6. Li, Y., Wang, M., Xu, H., Zhang, Y., Wang, D., "Force Analysis of Lining Structure for Subway Tunnel with Crack Disease". China Railway Science, 35(3), 2014, pp. 64-69.

7. Ansell, A., "Investigation of shrinkage cracking in shotcrete on tunnel drains". Tunnelling and Underground Space Technology , 25(5), 2010, pp. 607-613.

8. Bosco, C., Carpinteri, A., "Fracture behavior of beam cracked across reinforcement". Theoretical and applied fracture mechanics, 17(1), 1992, pp. 61-68.

9. Yang, S., Zhong, P., Zhang, J., "The influence of steel bar on crack extension of concrete faced rock-fill dam". Journal of hydroelectric engineering, 24(5), 2005, pp. 45-48.

10. Azad, A. K., Mirza, M. S., Chan, P., "Fracture energy of weakly reinforced concrete beams". Fatigue \& Fracture of Engineering Materials \& Structures, 12(1), 1989, pp. 9-18.

11. Ruiz, G., Elices, M., \& Planas, J., "Experimental study of fracture of lightly reinforced concrete beams". Materials and Structures, 31(10), 1998, pp. 683-691.

12. Chambel, P., Martins, R. F., Reis, L., "Fatigue crack growth under Mode I, II and III for plane-strain and plane-stress conditions". Procedia Engineering, 74, 2014, pp. 232-235.

13. Rabold, F., Kuna, M., Leibelt, T., "Complex network clustering by multiobjective discrete particle swarm optimization based on decomposition". Advanced Finite Element Methods and Applications, 66, 2013, pp. 355-374.
14. Rabold, F., Kuna, M., "Automated finite element simulation of fatigue crack growth in three-dimensional structures with the software system ProCrack". Procedia materials science, 3, 2014, pp. 1099-1104.

15. Li, Y., Tao, H., Gao, Q., "Parametric simulation method for 3-D non-planar crack propagation". Journal of Aerospace Power, 32(12), 2017, pp. 78-85.

16. Bremberg, D., Faleskog, J., "A numerical procedure for interaction integrals developed for curved cracks of general shape in 3D". International Journal of Solids and Structures, 62, 2015, pp. 144-157.

17. Xu, M., "The Applicational Study of Fracture Mechanics in Lining Cracking of Highway Tunnel". Master thesis of Chongqing jiaotong University, China, 2008, pp.37-43.

18. Xu, S., Liu, J., Zhang, X., "Double-K fracture theoretical analysis and crack width calculation of hydraulic pressure tunnel linng". China Civil Engineering Journal, 43(1), 2010, pp. 114-124.

19. Fan, J., Zhu, Z., "Study on the Effect of Different Flat Ratio on Tunnel Stability Based on Extended Finite Element Method". Construction Technology, 45(1), 2016, pp. 80-84.

20. Huang, H., Liu, D., Xue, Y., Wang, P., Liu, Y., "Numerical analysis of cracking of tunnel linings based on extended finite element". Chinese Journal of Geotechnical Engineering, 35(2), 2013, pp. 266-275.

21. Zhang, Y., Li, Z., "2D finite element analysis of bearing capacity of tunnel lining with cracks". Rock And Soil Mechanics, 26(8), 2005, pp. 1201-1206.

22. Li, Z., Zhang, Y., "Stability analysis for tunnels with cracked linings and the techniques for repairing the cracked linings". Modern Tunnelling Technology, 41(1), 2004, pp. 26-31.

23. Wang, Y., Liu, Z., Zhang, S., Qiu, J., Xie, Y., "A Fracture Mechanics-based Approach for Crack Stability Analysis of Liner in Highway Tunnel". China Journal of Highway and Transport, 28(7), 2015, pp. 77-85

24. Wang, H., Li, N., "Stiffness checking and reinforcement of tunnel lining with cracks". Journal Of Chang'an University(natural Science Edition), 29(1), 2009, pp. 64-68.

25. Chen, C., Yao, H., Jin, Z., "KI Calibration of Arch Three-point Bending Crack Specimens". Scientific Research Publishing, 19(1), 1974, pp. 41-45. 